\title{
AT-TARBAWI
}

At-Tarbawi: Jurnal Pendidikan, Sosial dan Kebudayaan

Volume 6 Nomor 1 Tahun 2019

doi: 10.32505/tarbawi.v6i1.893

\section{Kontribusi Perilaku Kepemimpinan dan Komitmen Lembaga untuk Meningkatkan Kinerja Dosen IAIN Langsa}

\author{
Yusaini \\ IAIN Langsa \\ m.pd_yusaini@yahoo.com
}

\begin{abstract}
To contribute to the effort to improve the performance of Langsa IAIN lecturers, one needs to do a study of various factors, especially leadership behavioural factors and institutional commitment. To find out empirically, it is necessary to research: Contribution of Leadership Behavior in Strengthening Institutional Commitments and Lecturer Performance at IAIN Langsa. The study aims to see whether there is an influence of leadership behaviour on efforts to improve lecturer performance, is there any influence of leadership behaviour on the commitment of institutions, and is there any influence of the commitment of capable institutions on the performance of lecturers at IAIN Langsa To capture the information, three instruments were designed, using a questionnaire. Questionnaires for leadership variables consisted of 17 questions, a commitment questionnaire for 12 questions, and a lecturer performance questionnaire of 16 questions. This questionnaire was distributed to all lecturers who were determined as a sample of 100 lecturers, from a total population of 384 people. The data analysis used in this study is to use the Regression Matrix Y on X (Standardized) statistical test. The results of the analysis provide conclusions that 1) Leadership behaviour has a positive effect on institutional commitment; 2) Leadership behaviour has a positive effect on the performance of lecturers and;3) Institutional commitment has a positive effect on the performance of lecturers.
\end{abstract}

Keyword: Leadership behaviour, institutional commitment, and lecturer performance

\begin{abstract}
Abstrak
Untuk memberikan kontribusi dalam upaya peningkatan Kinerja dosen IAIN Langsa, salah satu perlu dilakukan pengkajian terhadap berbagai faktor, terutama faktor perilaku kepemimpinan dan komitmmen lembaga. Untuk mengetahui secara empiris, maka perlu dilakukan suatu penelitian tentang: Kontribusi Perilaku Kepemimpinan Dalam Memperkuat Komitmen Lembaga dan Kinerja Dosen di IAIN Langsa. Penelitian bertujuan untuk melihat adakah pengaruh perilaku kepemimpinan terhadap upaya peningkatan kinerja dosen, adakah pengaruh perilaku kepemimpinan terhadap komitmen lembaga, dan adakah pengaruh komitmen lembaga mampu terhadap kinerja dosen di IAIN Langsa. Untuk menjaring informasi tersebut dirancang tiga perangkat instrumen, yaitu dengan mengunakan angket. Angket variabel kepemimpinan terdiri dari 17 butir pertanyaan, angket komitmen lembaga 12 pertanyaan, dan angket kinerja dosen 16 butir pertanyaan. Anket ini dibagikan kepada seluruh dosen yang ditetapkan sebagai sampel berjumlah 100 orang dosen, dari jumlah populasi 384 orang. Analisis data yang gunakan dalam penelitian ini adalah menggunakan uji statistik Reggression Matrix $Y$ on X (Standardized). Hasil analisis memberikan kesimpulan bahwa: 1) Perilaku kepemimpinan berpengaruh positif terhadap komitmen lembaga; 2) Perilaku kepemimpinan berpengaruh positif terhadap kinerja dosen dan; 3) Komitmen lembaga berpengaruh positif terhadap kinerja dosen.
\end{abstract}

Kata Kunci: Perilaku kepemimpinan, komitmen lembaga, dan kinerja dosen 


\section{A. Pendahuluan}

Kepemimpinan merupakan faktor penting dalam perjalanan suatu sistem lembaga pendidikan terhadap pencapaian tujuan lembaga, karena kepemimpinan adalah orang yang berpengetahuan dan berpengalaman untuk memengaruhi orang lain agar mau mengikuti keinginannya dalam pencapaian suatu tujuan. Pimpinan pada perguruan tinggi merupakan orangorang terpilih yang dijadikan sebagai leader yang berperan mensukseskan tujuan lembaga yang hendak dicapai.

Pemimpin di perguruan tinggi adalah orang yang dapat mempengaruhi orang yang dipimpinnya, agar bekerja dengan baik demi ketercapaian tujuan lembaga. Semua kinerja karyawan dan dosen pada perguruan tinggi berpengaruh pada perilaku kepemimpinan yang diterapkan. Pemimpin yang berhasil pada perguruan tinggi, adalah sejauhmana kemampuannya mempengaruhi dan mengawasi orang-orang yang diperintahkan di sekitarnya. Kemampuan pemimpin adalah kompetensi yang dimiliki untuk mempengaruhi orang yang ada di sekelilingnya dalam bekerja. Robbins, S.P dan Mary Coulter (2007), Siswanto (2008), Badani (2014), sehingga keberhasilan sebuah perguruan tinggi dalam mencapai tujuan, visi dan misi bukanlah semata-mata bergantung pada besarnya anggaran yang dimiliki dan fasilitas kampus yang maha mengagumi, akan tetapi keberhasilan perguruan tinggi bergantung pada perilaku pemimpin dalam menjalankan roda kepemimpinannya.

Kepemimpinan dalam organisasi dan kehadiran pemimpin sebagai pemberi inspirasi dalam organisasi merupakan sesuatu yang penting. Karena kepemimpinan itu sendiri adalah proses interaksi antar manusia dan ia bisa juga disebut aktivitas kehidupan. Maka untuk menciptakan kehidupan dalam sebuah perguruan tinggi diperlukan pimpinan yang efektif. Perilaku kepemimpinan di IAIN Langsa menjadi harapan semua orang dalam meningkatkan kinerja dosen dan memperkuat komitmen lembaga. Oleh karena itu, upaya tersebut menjadi harapan semua pihak untuk memperoleh informasi tentang perilaku kepemimpinan yang serasi, sepadan, dan menjadi 
kepemimpinan yang diharapkan dalam rangka meningkatkan kinerja dosen dan memperkuat komitmen lembaga.

Kinerja merupakan suatu istilah yang sering digunakan untuk mengukur kemampuan kerja. Baik buruk seseorang dalam melaksanakan pekerjaan pada satu rentang waktu sering disebut dengan kinerja. Kinerja adalah suatu kemampuan yang ditunjukkan oleh seseorang dalam melaksanakan sesuatu atau tugas yang sedang dikerjakan. Tugas juga sering diukur dan dikaitkan dengan istilah kinerja. Tanggung jawab Secara pribadi atau individu adalah tanggung jawab secara hati nurani manusia dalam komitmen kerja. Sebuah pekerjaan secara individual memiliki target dan kepuasan diri apabila pekerjaan telah dapat diselesaikan. Tanggung jawab secara instansi merupakan tuntutan keadilan antara hak dan kewajiban. Pekerjaan perlu ditunjukkan kepada siapa ia harus bertanggungjawab. Semakin baik tanggung jawab yang dapat ditunjukkan, maka semakin baik pula hak yang bisa ia dapatkan, hal ini biasanya ditunjukkan dengan prestasi kerja.

Kinerja merupakan hasil yang diperoleh oleh sebuah lembaga, organisasi, departemen, atau suatu kelompok yang bersifat profit atau non profit oriented yang diperoleh selama masa tertentu. Kinerja adalah realisasi suatu pekerjaan yang mempunyai korelasi dengan visi, misi dan tujuan dari suatu organisasi, kepuasan konsumen, dan memberikan kontribusi ekonomi (Fahmi, I., 2014:127). Dengan demikian kinerja berkaitan dengan hasil pekerjaan yang hubungannya dengan pelayanan dan finansial. Artinya, kinerja memiliki tuntutan hak yang harus diberikan agar pelayanan melalui suatu pekerjaan akan dilakukan.

Tampubolon., B.D. (2007:106) juga menuliskan bahwa kinerja perorangan dengan kinerja lembaga atau kinerja organisasi memiliki korelasi yang kuat. Dalam arti bahwa bila kinerja karyawan (individual performance) baik maka kemungkinan besar kinerja organisasi (corporate performance) juga baik. Kinerja seorang karyawan akan baik bila ia mempunyai keahlian (skill) yang tinggi, bersedia bekerja karena gaji atau diberi upah sesuai 
dengan perjanjian dan mempunyai harapan (expectation) masa depan lebih baik (Prawirosentono, 1999).

Banyak faktor yang mempengaruhi kinerja serta memiliki peran masing-masing dalam memberikan kontribusi untuk mempengaruhi kinerja. Colquitt A. Jasson, Lipine A. Jeffery dan Wesson J. Michael (2009:24), menjelaskan bahwa banyak faktor yang mempengaruhi kinerja, seperti Organizational Mechanism, Group Mechanisms, Individual Characteristics, Individual Mechanisms, Individual Outcomes yang digambarkan dalam Integrative Model of Organizational Behavior. Wibowo (2007:6) juga menggambarkan bahwa faktor-faktor yang mempengaruhi kinerja, yaitu:

1. Personal factor, ditunjukkan oleh tingkat keterampilan, kompetensi yang dimiliki, motivasi, dan komitmen individu.

2. Leadership factors, ditentukan oleh kualitas dorongan, bimbingan, dan dukungan yang dilakukan manajer dan team leader.

3. Team Factors, ditunjukkan oleh kualitaas dukungan yang diberikan oleh rekan kerja.

4. System Factors, ditunjukkan oleh adanya sistem kerja dan fasilitas yang diberikan oleh organisasi.

5. Contextual/Situational Factors, ditunjukkan oleh tingginya tingkat tekanan dan perubahan lingkungan internal dan eksternal.

Kinerja karyawan dapat ditingkatkan tidak terlepas dari komitmen lembaga/organisasi yang akan mendorong munculnya kebiasaan karyawan dalam mendukung perusahaan atau lembaga untuk bekerja lebih efektif dan efisien. Karyawan yang memiliki komitmen tinggi terhadap organisasi akan berorientasi pada pekerjaan, merasa dekat dengan organisasi dan organisasi sebagai tempat pemenuhan kebutuhan personal mereka. Maka mereka cenderung mengerahkan segala upaya demi perusahaan dan akan menimbulkan kepuasan dari apa yang telah mereka lakukan. Hal ini sesuai dengan pendapat Ursa Majorsy (2001:67) yang mendefinisikan komitmen sebagai suatu keadaan dimana seorang karyawan memihak pada suatu organisasi tertentu serta berniat memelihara keanggotaannya dalam 
organisasi tersebut. Ini menunjukan bahwa komitmen yang tinggi pada organisasi dapat dilihat dari loyalitas karyawan pada organisasi yang mempekerjakannya juga tinggi. Karyawan yang memiliki komitmen organisasi yang tinggi akan lebih termotivasi untuk hadir dalam organisasi dan berusaha mencapai tujuan organisasi.

Banyak organisasi runtuh dan bubar disebabkan pemimpin tidak mampu menyelesaikan, mengarahkan dan mengendalikan orang-orang yang berada di sekelilingnya. Banyak karyawan kacau, bertengkar, saling menuduh, dan tidak merasa puas dalam bekerja dikarenakan pemimpin yang tidak mampu memimpin. Oleh karena itu, Rivai, V dan Sylviana Murni (2012) menjelaskan dalam buku Education Management bahwa: Kepemimpinan yang berkualitas sangat mudah dalam meletakkan dasar kepercayaan terhadap orang di sekelilingnya, sementara organisasi yang tidak memiliki kepemimpinan berkualitas sulit untuk mendapatkan kepercayaan dari para anggotanya dalam menyelesaikan pekerjaan. Organisasi tersebut akan kacau dan tujuan organisasi tidak akan tercapai. Robbins, S dan Mary Coulter (2009:178), menjelaskan tujuh ciri berkaitan pada seorang pemimpin yang sukses, adalah:

1. Dorongan. Pemimpin harus mampu memberikan tingkat usaha yang tinggi. Pemimpin harus memiliki kehendak yang tinggi untuk pencapaian prestasi, mereka harus ambisius, mereka memiliki banyak energi, mereka tidak mengenal lelah dan letih dalam bekerja, dan mereka menunjukkan insiatif.

2. Kehendak Untuk Memimpin. Pemimpin memiliki keinginan kuat untuk mempengaruhi dan memimpin orang di sekitarnya dalam organisasi. Mereka punya kemauan menjunjung tinggi tugas tanggungjawab.

3. Kejujuran dan Integritas. Pemimpin membangun hubungan saling mempercayai antara mereka dan pengikutnya dengan menjadi jujur dan tidak menipu, serta dengan menunjukkan konsistensi yang tinggi antara perkataan dan perbuatan.

4. Kepercayaan Diri. Para pengikut melihat pemimpinnya tidak ragu akan dirinya. Oleh karena itu, pemimpin perlu menunjukkan kepercayaan diri 
untuk meyakinkan pengikutnya tentang kebenaran sasaran dan keputusannya.

5. Kecerdasan. Pemimpin haruslah cukup cerdas untuk mengumpulkan, menganalisis dan menafsirkan banyak informasi, dan mereka perlu mampu untuk menciptakan visi, memecahkan masalah, dan membuat keputusan yang tepat.

6. Pengetahuan yang terkait dengan pekerjaan. Pemimpin yang efektif mempunyai tingkat pengetahuan yang tinggi tentang perusahaan, industri, dan hal-hal teknis. Pengetahuan yang mendalam membuat pemimpin dapat membuat keputusan yang terinformasi dengan baik dan memahami akibat-akibat yang dialami keputusan itu.

7. Versi Tambahan. Pemimpin adalah orang yang enerjik dan bersemangat. Mereka adalah orang yang mampu bersosialisasi, tegas dan jarang diam atau menyerah.

\section{B. Metode}

Penelitian ini digolongkan dalam jenis penelitian mixed methods untuk melihat hubungan secara kualitatif dan kuantitatif, karena tujuan penelitian ini adalah untuk mengungkapkan suatu hubungan kausalitas antar variabel penelitian dan mencari berapa besar hubungan antar variabel yang dikaji. Penelitian dilakukan pada empat (4) Fakultas di IAIN Langsa, populasi adalah seluruh dosen IAIN Langsa yang aktif melakukan proses pembelajaran pada tahun akademik 2016/2017. Penentuan sampel secara Proportional Randoms Sampling berdasarkan rumus Solvin dengan jumlah sampel sebanyak 115 orang.

Instrumen yang digunakan dalam penilitian ini berupa kuesioner dalam bentuk instrumen angket tertutup dengan lima pilihan model skala Likert. Indikator pada masing-masing variabel sudah diuji validitas dan reliabilitas untuk selanjutnya dilakukan ujicoba. Analisis hasil ujicoba instrumen dilakukan dengan menggunakan rumus Product Moment Data hasil penelitian dianalisis secara deskriptif kualitatif dan kuantitatif (analisis jalur). Aplikasi analisis jalur dalam penelitian ini menggunakan program 
LISREL dengan model sederhana dan menggunakan data interval.

\section{Hasil dan Pembahasan}

1) Hasil Analisis Deskriptif

Berdasarkan hasil analisis kuesioner, diketahui bahwa variabel perilaku kepemimpinan memperoleh rata-rata skor tertinggi sebesar 4,41 dan skor terendah sebesar 4,01. Pada variabel komitmen lembaga/organisasi item pernyataan kuesioner menunjukkan skor rata-rata item pernyataan berada pada skor tertinggi sebesar 4,4 dan skor terendah sebesar 4,0. Sedangkan variabel kinerja dosen pada masing-masing item pernyataan kuesioner menunjukkan skor rata-rata item pernyataan berada pada skor tertinggi sebesar 4,4 dan skor terendah sebesar 4,02. Adapun ratarata skor antar variabel yang dianalisis berdasarkan kriteria dapat dilihat pada tabel berikut:

Tabel 1. Kriteria Skor Antar Variabel

\begin{tabular}{|c|c|c|c|c|c|c|}
\hline \multirow[b]{2}{*}{ No } & \multirow[b]{2}{*}{ Variabel } & \multicolumn{3}{|c|}{ Kriteria Skor } & \multirow{2}{*}{$\begin{array}{c}\text { \% Skor } \\
\text { Antar } \\
\text { Variabe } \\
1\end{array}$} & \multirow{2}{*}{$\begin{array}{c}\text { Kategori } \\
\text { Penilaia } \\
\mathbf{n}\end{array}$} \\
\hline & & $\begin{array}{l}\text { Sanga } \\
\text { t Baik }\end{array}$ & Baik & $\begin{array}{l}\text { Cukup } \\
\text { Baik }\end{array}$ & & \\
\hline 1 & $\begin{array}{l}\text { Perilaku } \\
\text { Kepemimpinan }\end{array}$ & $30 \%$ & $55 \%$ & $15 \%$ & $4,16 \%$ & $\begin{array}{l}\text { Sangat } \\
\text { Baik }\end{array}$ \\
\hline 2 & Komitmen Lembaga & $29 \%$ & $57 \%$ & 145 & $4,16 \%$ & $\begin{array}{c}\text { Sangat } \\
\text { Baik }\end{array}$ \\
\hline 3 & Kinerja Dosen & $30 \%$ & $56 \%$ & $14 \%$ & $4,15 \%$ & $\begin{array}{l}\text { Sangat } \\
\text { Baik }\end{array}$ \\
\hline
\end{tabular}

2) Hasil Analisis Jalur

Aplikasi analisis jalur dalam penelitian ini menggunakan program LISREL dengan model sederhana dan menggunakan data interval. Output yang dihasilkan dalam penelitian ini adalah sebagai berikut:

\section{a. Covarian Matrix}

Kovarian matriks antara variabel $\mathrm{Y}$ dengan variabel $\mathrm{Y}$ itu sendiri sebesar 19,78., Y dan Z sebesar 15,79., dan variabel Y dengan variabel $X$ sebesar 19,78. Kovarian antara variabel $Z$ dengan variabel $Z$ itu sendiri sebesar 22,03., dan variabel $\mathrm{Z}$ dengan variabel $\mathrm{X}$ sebesar 9,82, dan 
kovarian variabel X dengan variabel X sendiri sebesar 21,46. Kovarian matriks menunjukkan hubungan linier yang terjadi diantara dua variabel. Nilai kovarian matrik tersebut tidak nol, ini menunjukkan bahwa antar variabel yang dianalisis menunjukkan hubungan linier positif.

\section{b. Structural Equations}

Ada dua Structural Equation yang dihasilkan oleh output LISREL. persamaan struktural yang dihasilkan yaitu:

$$
\begin{array}{lll}
\mathrm{Y}=0.22^{*} \mathrm{X} & \text { Error var }=18.78 & \mathrm{R}^{2}=0.51 \\
(0.088) & (2.50) \\
2.45 & 7.52
\end{array}
$$

Persamaan struktural tersebut menunjukkan bahwa variabel perilaku kepemimpinan berpengaruh terhadap komitmen lembaga sebesar 0,22 dan standar error sebesar 0,088 . Pengaruh tersebut signifikan dimana thitung $>$ t-tabel, t-hitung $=2,45$, t-tabel $=1,66$, koefisien determinasi $\left(\mathrm{R}^{2}\right)$ sebesar 0,51 artinya variabel perilaku kepemimpinan mempengaruhi variabel komitmen lembaga sebesar 51\%. Sedangkan sisanya sebesar 49\% dipengaruhi oleh variabel lain yang tidak dilibatkan dalam penelitian ini. Sedangkan persamaan struktural yang kedua yang dihasilkan adalah:

$$
\begin{array}{lll}
\mathrm{Z}=0.73^{*} \mathrm{Y}+0.30 * \mathrm{X} & \text { Error var. }=7.58 & \mathrm{R}^{2}=0.66 \\
(0.060) & (0.057) & (1.01) \\
12.18 & 5.23 & 7.52
\end{array}
$$

Persamaan struktural tersebut menunjukkan variabel komitmen lembaga secara parsial mempengaruhi variabel kinerja dosen sebesar 0,73 pengaruh tersebut signifikan dimana $\mathrm{t}$-hitung $>\mathrm{t}$-tabel, $\mathrm{t}$-hitung $=$ 12,18 , dan t-tabel $=1,66$, sedangkan variabel perilaku kepemimpinan secara signifikan mempengaruhi variabel kinerja dosen sebesar 0,30. Dari persamaan struktural menunjukkan bahwa variabel perilaku kepemimpinan dan variabel komitmen lembaga secara signifikan mempengaruhi variabel kinerja dosen sebanyak $66 \%$. 


\section{c. Regression Matrix Y on X (Standardized)}

Matrik ini merupakan gabungan dari matriks BETA dan GAMMA. Dimana nilai 0,22 yang merupakan besarnya pengaruh variabel perilaku kepemimpinan terhadap variabel komitmen lembaga, sedangkan nilai sebesar 0,45 (besarnya pengaruh variabel perilaku kepemimpinan terhadap variabel kinerja dosen) didapat dari perhitungan $(0,69 \times 0,22)+$ $(0,30)=0,45$.

\section{d. Total and Indirect Effects}

Untuk mengetahui pengaruh langsung, pengaruh tidak langsung dan pengaruh total dapat dilihat dari matrik Total and inderect effect, Hasil tersebut dapat dilihat pada tabel berikut:

Tabel 2. Pengaruh Langsung, Tidak Langsung dan Pengaruh Total

\begin{tabular}{|l|c|c|c|}
\hline \multicolumn{1}{|c|}{ Hubungan Struktural } & $\begin{array}{c}\text { Pengaruh } \\
\text { Langsung }\end{array}$ & $\begin{array}{c}\text { Pengaruh } \\
\text { Tidak } \\
\text { Langsung }\end{array}$ & $\begin{array}{c}\text { Total } \\
\text { Pengaru } \\
\text { h }\end{array}$ \\
\hline Perilaku (X) - Komitmen (Y) & 0,22 & - & 0,22 \\
\hline Perilaku (X) - Kinerja (Z) & 0,30 & $\begin{array}{c}0,22 * 0,73= \\
0,16\end{array}$ & 0,46 \\
\hline Komitmen (Y) - Kinerja (Z) & 0,73 & - & 0,73 \\
\hline
\end{tabular}

\section{e. Diagram Path}

Model Estimate

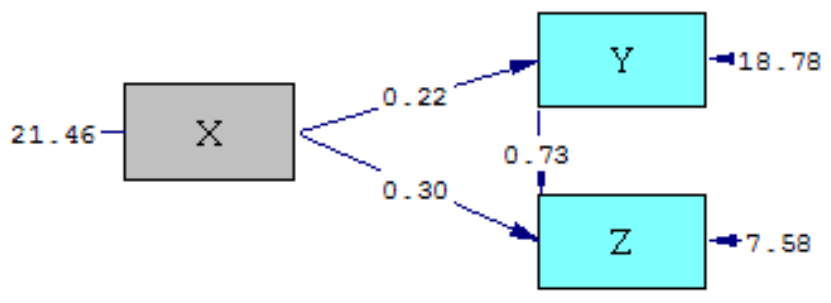

Chi-Square $=0.00, \mathrm{df}=0, \mathrm{P}-\mathrm{value}=1.00000, \mathrm{RMSEA}=0.000$

Gambar 1. Path Diagram Estimate 
t-value

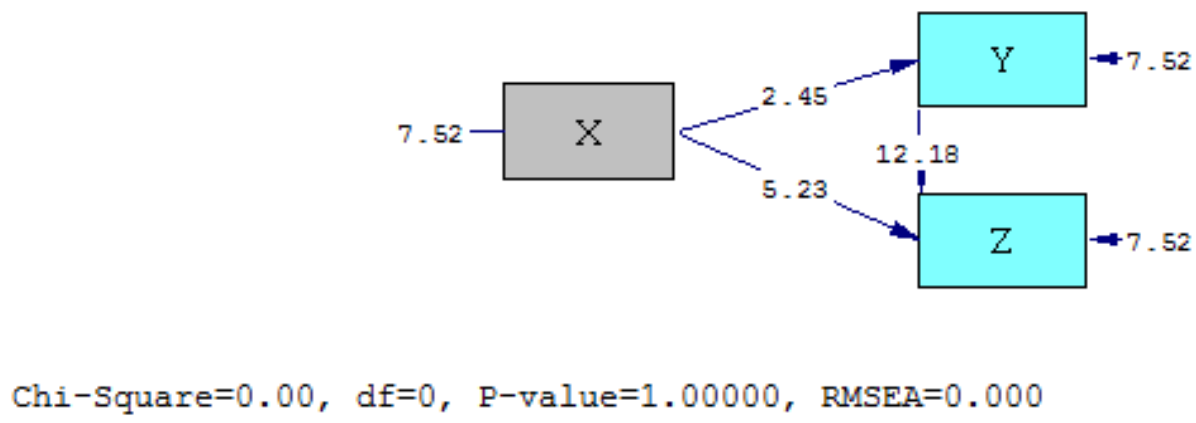

Gambar 2. Path Diagram t-Value

Diagram path di atas dapat diketahui apakah variabel eksogen mempunyai pengaruh terhadap variabel endogen, yakni dengan melihat angka yang ada pada diagram tersebut, apabila t-hitung yang dihasilkan LISREL < dari t-tabel, maka variabel tersebut tidak berpengaruh. Sebaliknya apabila t-hitung yang dihasilkan LISREL > dari t-tabel, maka variabel tersebut berpengaruh.

\section{Kesimpulan}

Berdasarkan hasil analisis data dan pengujian hipotesis dapat disimpulkan bahwa perilaku kepemimpinan berkontribusi positif terhadap komitmen lembaga sebesar 51\% sedangkan sisanya sebesar 49\% dipengaruhi oleh variabel lain. Perilaku kepemimpinan dan komitmen lembaga secara signifikan mempengaruhi variabel kinerja dosen sebanyak $66 \%$.

\section{DAFTAR PUSTAKA}

Abdillah, A.C. 2010.dan Wajdi, F. Pengaruh Kepemimpinan, Stres Kerja, Disiplin Kerja, dan Kompensasi Dengan Kinerja Pegawai, Daya Saying. Jurnal Ekonomi Manajemen Sumber Daya, 12, (1), 1-11.

Belferik Manullang. 2006, Kepemimpinan Pedagogis (Membangun Karakter Sumber Daya Manusia, Medan: Program Pascasarjana, Universitas Negeri Medan. 
Badani. 2014. Kepemimpinan dan Perilaku Organisas. Bandung: Alfabeta.

Chairy, L.S. 2002. Seputar Komitmen Organisasi, Makalalah disampaikan dalam Acara Arisan Angkatan '86 FPsi.UI. Jakarta, 8 September 2002.

Colquitt, J.A., Jeffery A. LePine dan Michael J. Wesson. 2009. Organization Behavior: Improving Performance and Commitment in the Workplace, New York: McGraw-Hill.

Herlambang, S. 2014. Perilaku Organisasi, Cara mudah Mempelajari Perilaku Manusia Dalam Sebuah Organisasi. Yogyakarta: Gosyen Publishing.

Lina, D. (2012). Analisis Pengaruh Kepemimpinan Dan Budaya Organisasi Terhadap Kinerja Pegawai Dengan Sistem Reward Sebagai Variabel Moderating, Jurnal Riset Akuntansi, 14, (1), 2014, p. 77-97.

Lussier, R.N. 1997. Management: Concepts, applications, skill development. Ohio: South-Western College Publishing.

Majorsy, U. 2007. Kepuasan kerja, Semangat Kerja dan Komitmen Organisasional Pada Staf Pengajar Universitas Gunadarma. Jurnal Psikologi, 1(1), p. 63-74.

Purnomo, H., Cholil., M. 2010. Pengaruh Gaya Kepemimpinan Terhadap Kepuasan Kerja Berdasarkan Motivasi Kerja Pada Karyawan Administratif Di Universitas Sebelas Maret Surakarta, Jurnal Manajemen Sumberdaya Manusia 4, (1), p. 27-35.

Rejeki, M.E.S. 2012. Pengaruh komitmen organisasi dan gaya kepemimpinan terhadap Hubungan antara partisipasi anggaran dan kinerja manajerial, jurnal LANTIP 2, (01), p. 1-11.

Rivai, V. Dan Sylviana Murni. 2012. Education Management, Jakarta: PT. Rajagrafindo Persada.

Robbins, S.P. dan Mary Coulter. 2007. Manajemen, Edisi kedelapan, Jilid 2, Jakarta: PT. Indeks.

Suyasa, S. 2008. Komitmen Organisasi dan Organizational Citizenship Behavior pada Karyawan Call Centre di PT. Phronesis Jurnal Ilmiah Psikologi Industri dan Organisasi, 10, (2), p. 154-169

Siswanto. 2008. Pengantar Manajemen. Jakarta: PT. Bumi Aksara.

Silalahi, U. 2011. Azas-Azas Manajemen, Bandung: Refika Aditama. 
Septiana, R., Ngadiman, dan Elvia Ivada. 2013. Pengaruh Kepemimpinan Kepala Sekolah dan Motivasi Kerja Terhadap Kinerja Guru SMP Negeri Wonosari. Jurnal Jupe UNS, 2, (1), p. 107-118.

Tampubolon, D.B. 2007. Analisis Faktor Gaya Kepemimpinan dan Faktor Etos Kerja. Jurnal Standardisasi, Vol. 9 (3), 106 - 115.

Tim Dosen Administrasi Pendidikan. 2012. Manajemen Pendidikan. Bandung: Alfabeta.

Torang, S. 2013. Organisasi dan Manajermen (Perilaku, Struktur, Budaya dan Perubahan Organisasi. Bandung: Alfabeta.

Wibowo. Manajemen Kinerja, Edisi kempat. Jakarta: P.T. RajaGrafindo Persada.

Yulk, G. 2010. Kepemimpinan Dalam Organisasi, Edisi Kelim. Jakarta: PT. Indeks. 
